\title{
Scottish Consortium for Development and Education in Dental Primary Care
}

\author{
J. E. Clarkson, ${ }^{1}$ M. Murray, ${ }^{2}$ N. B. Pitts, ${ }^{3}$ T. W. MacFarlane, ${ }^{4}$ J. P. Newton, ${ }^{5}$ F. J. T. Burke, ${ }^{6}$ \\ C. A. Bain, ${ }^{7}$ R. Ibbetson, ${ }^{8}$ J. S. Rennie ${ }^{9}$
}

A national consortium for dental primary care in Scotland has been formed as a result of integrated planning by groups involved in managing and delivering postgraduate dental education in Scotland. In 1998 a partnership was formed with representatives from the Scottish Council for Postgraduate Medical and Dental Education (SCPMDE) and the three Scottish dental institutions at Dundee, Edinburgh and Glasgow Universities. The principal aim of the Consortium is to promote evidence-based dental care through postgraduate education and research. The activities of the Consortium will provide a broadly based adjunct to current postgraduate provision with partner institutions contributing in different ways. Since its inception the Consortium has focused on two main areas:

- 'Higher Training' for Primary Care.

- Scottish Dental Practice Based Research Network
'Higher training' for primary care In order to facilitate a more structured career pathway for practitioners in dental primary care, SCPMDE has established Priyears' duration. The aims of the Fellowships are to equip potential leaders of the next generation of general dental practitioners with an understanding of the evidence base supporting appropriate clinical practice and the skills needed to advance education in dental primary care in the next century. The training fellows are currently enrolled on a Masters programme in Primary Care at either Dundee or Glasgow University, with the new Postgraduate Dental Institute of the University of Edinburgh offering places in October 2000. mary Care Training Fellowships of two
The Masters courses have been specifically designed to cover aspects of dental primary care built around a restorative framework. There are learning objectives common to all the Masters programmes that include communication skills, multiprofessional learning, management, audit, research methodology and the development of critical appraisal skills. The Higher Training Fellows meet together on a Scottish basis for joint educational activities and to share experiences gained locally. Students have to produce a clinical portfolio and undertake a supervised research project that reflects their interests. The clinical teaching and supervision by a variety of specialists. The portfolio of clinical cases is component of the course includes direct

${ }^{1}$ Senior Lecturer in Dental Primary Care, Dental Health Services Research Unit, Dental Hospital and School, Dundee Dental Hospital \& School, University of Dundee, Park Place, Dundee DDI 4HR; ${ }^{2}$ Senior Lecturer in Dental Primary Care, Dental Hospital and School, University of Glasgow, 378 Sauchiehall Street, Glasgow G2 3JZ; ${ }^{3}$ Director, Dental Health Services Research Unit, Dental Hospital and School, Dundee Dental Hospital \& School, University of Dundee, Park Place, Dundee DDI 4HR; ${ }^{4}$ Dean, Dental Hospital and School, University of Glasgow, 378 Sauchiehall Street, Glasgow G2 3JZ; ${ }^{5}$ Senior Lecturer in Integrated Oral Care, Dundee Dental Hospital \& School, University of Dundee, Park Place, Dundee DDI 4HR; ${ }^{\circ}$ Professor of Dental Primary Care, The University of Birmingham, School of Dentistry, St Chad's Queensway Birmingham B4 $6 \mathrm{NN}$; ${ }^{7}$ Senior Lecturer in Dental Primary Care, Dental Hospital and School, University of Glasgow, 378 Sauchiehall Street, Glasgow G2 3JZ; ${ }^{8}$ Director, Edinburgh Postgraduate Dental Institute, The University of Edinburgh Lauriston Building, Lauriston Place, Edinburgh EH39YW; ${ }^{9}$ Dental Director, Scottish Council for Postgraduate Medical and Dental Education, 4th Floor, Hobart House, 80 Hanover Street, Edinburgh EH2 I EL REFEREED PAPER

Received 09.12.99; Accepted 12.01.00

(C) British Dental Journal 2000; 189: 222-223
In brief

- The Scottish Consortium for Development and Education in Dental Primary Care comprises a partnership of groups delivering postgraduate education in Scotland.

- The principal aim is to promote evidence-based dental care through postgraduate education and research.

- Current activity includes providing Higher Training Fellowships in Dental Primary Care and developing the Scottish Dental Practice Bases Research Network.

expected to exhibit a range of treatments with the supporting evidence for their effectiveness. The variation, quality and presentation of the clinical cases will be of a standard required for MGDS examination. The research component includes the teaching of research methodology and the principles of integrating evidence-based dentistry into clinical practice. Students are encouraged to undertake a research project with direct relevance to the provision of dental primary care in Scotland. Currently these include the effect of educational outreach on the implementation of clinical guidelines, the efficacy of cross infection procedures in the sterilisation of matrix bands, the use and limit of imaging in implant dentistry, evaluation of a scheme to facilitate the access of institutionalised elderly to routine dental care and the effect of different core materials on fracture resistance of dentine-bonded crowns.

The Consortium advertises annually for students and successful candidates are able to express a preference for the institute that would suit them best. Training fellows have a base in an appropriate practice or in a recognised Community Dental Officer post where they are expected to provide a service contribution of the order of five clinical sessions. In return, the practice must provide a supportive environment for the student to develop and mature. The Training Fellows receive a salary based pro rata $(50 \%)$ on the base point of the Specialist Registrar grade 
and receive remuneration from the training practice or CDS Trust.

\section{Scottish Dental Practice Based Research Network}

The recent SCPMDE strategic review perceived the need to develop research in primary care in dentistry while the National Health Service in Scotland's R\&D Strategy seeks to ensure that an 'evaluative culture' pervades all aspects of the NHS, including dental primary care. Currently the evidence base for dental primary care is limited and one reason for this is that the research skills of academic institutions have traditionally focused on conducting primary research in specialist areas rather than on research in the primary care context.

Across Scotland networks of dentists participating in research have evolved such as the Scotland-wide group of practices which supported the Strategies for Caries Control study run from Dundee between 1994-1997 and the more recent and ongoing Glasgow Research Initiative in Dental Practice (GRID). These initiatives have gradually increased the number of dentists involved at all levels of research, from data collection to project leadership and grant holder status. At the present time, these groups are working in isolation of each other and there is no structured framework for dentists interested in either participating or developing research in dental primary care in Scotland. In order to overcome some of these problems and generate high quality research in dental primary care, the Scottish Dental Practice Based Research Network (PBRN) has been established. An on-line journal based at the Dental Health Services Research Unit is to be launched to aid communication and promote the network's activities. The remit of the Scottish Dental PBRN is to work Scotland-wide with established research groups and individuals to:

- Facilitate efficient communication.

- Establish a register of on-going research and research ideas.

- Support and provide appropriate education.

- Disseminate information relevant to providing evidence-based dental primary care.
- Provide advice on research methods and grant applications.

As the role of the Consortium develops there should be a greater input to the undergraduate course with more teaching on the principles of oral health care delivery. It is hoped that the Scottish Dental PBRN has a synergistic effect on the contribution of research and education to evidence-based dental primary care and that the Higher Training Fellows will be equipped to lead this arena in the future. At the new Postgraduate Dental Institute in Edinburgh post-qualification courses for the professions complementary to dentistry will come on stream during the year 2000 and co-ordination of this activity on a Scotland-wide basis will be undertaken. The Scottish Consortium for Development and Education in Dental Primary Care is unique in its structure and range of activities. As initial members of the Consortium we are excited by the opportunities ahead and look forward to updating the profession on our activities in due course. 